\title{
Hyperthermic Intraperitoneal Chemotherapy (HIPEC) for Ovarian Cancer: Evaluation of Side Effects in a Single Institution Cohort
}

\author{
MICHAEL FRIEDRICH ${ }^{1}$, WOLFGANG ZINN ${ }^{1}$, LAURA KOLNSBERG ${ }^{1}$, \\ CLAYTON KRAFT ${ }^{2}$ and WALTHER KUHN ${ }^{3}$ \\ ${ }^{1}$ Klinik für Frauenheilkunde und Geburtshilfe, Helios Klinikum, Krefeld, Germany; \\ ${ }^{2}$ Klinik für Orthopädie und Unfallchirurgie, Helios Klinikum, Krefeld, Germany; \\ ${ }^{3}$ Klinik für Frauenheilkunde und Geburtshilfe, DonauIsar Klinikum Deggendorf, Deggendorf, Germany
}

\begin{abstract}
Background/Aim: Peritoneal carcinomatosis is a sign of advanced ovarian cancer. If cytoreductive surgery results in a tumor-free situation with the remaining tumor being less than $0.25 \mathrm{~cm}$, Hyperthermic intraperitoneal chemotherapy (HIPEC) may further improve prognosis. Patients and Methods: Patients with ovarian cancer and peritoneal carcinomatosis underwent cytoreductive surgery. In 43 patients with optimal tumor debulking, HIPEC was performed. The peri- and post-operative course was observed. Adverse events were recorded after the Clavien-Dindo classification. Results: The median age of the patients was 56 years, the median peritoneal cancer index (PCI) was 13, and the median operation time was 356 min. There was no postoperative surgery associated death. No adverse events were recorded in 16 (37.2\%) of 43 patients, no grade III or IV adverse events were reported for $33(76.7 \%)$ patients, and no grade IV adverse events were reported for 41 (95.3\%) patients. Grade III adverse events occured in 19 (44.2\%) of the 43 patients. Grade IV adverse events occured in 3 (7.0\%) of the 43 patients. Conclusion: In ovarian cancer, multiple surgical procedures may be necessary in order to have macroscopically eradicated tumor tissue. The combination with HIPEC, further improves survival of patients with peritoneal carcinomatosis.
\end{abstract}

In Germany, epithelial ovarian cancer is the leading cause of gynecologic cancer mortality with 5,354 deaths and 7,250 new

This article is freely accessible online.

Correspondence to: Prof. Dr. med. Michael Friedrich, Klinik für Frauenheilkunde und Geburtshilfe, Helios Klinikum, Lutherplatz 40, 47805 Krefeld, Germany. Tel: +49 2151 322201, Fax: +49 2151 322220, e-mail: michael.friedrich@helios-gesundheit.de

Key Words: Hyperthermic intraperitoneal intraoperative chemotherapy, HIPEC, ovarian cancer, side effects, cisplatin. diseases of ovarian cancer in the year 2014. Most patients with advanced stage cancer will experience recurrence and die as a result. The five year relative survival for women diagnosed with stage FIGO III and IV epithelial ovarian cancer has changed little over the years and remains around 20-30\%. Thus, more effective treatment strategies are needed (1).

In most cases of advanced cancer the peritoneum is the primary site of spread and failure, even in relapses. In view of this, it seems logical to assess local treatment strategies apart from peritonectomy. Prior studies have shown that intraperitoneal delivery of cisplatin is associated with a 20 -fold higher concentration in the intraperitoneal space, compared to that measured in plasma after intravenous administration. Several randomized clinical trials have shown that postoperative intraperitoneal and intravenous (i.p./i.v.) chemotherapy improves survival in women with optimally resected stage III ovarian cancer compared with i.v. chemotherapy alone. Yet many factors have been identified as potential barriers to integration of i.p./i.v. chemotherapy into clinical routine. Treatment-related toxicities, adhesion barriers after surgery, dysfunction of implanted i.p. catheters (Tenckhoff catheters), the absence of a standard treatment regimen, patients" preference and the inconvenience of an inpatientegimen are some of the more frequently reported hinderances (2).

Hyperthermic intraperitoneal chemotherapy (HIPEC) is usually applied immediately following peritonectomy procedure with the aim of directly delivering a heated cytotoxic drug to the peritoneal surface of the abdomen. While cytoreductive surgery removes macroscopic disease, the purpose of HIPEC is to eradicate microscopic disease from the peritoneal surface. Studies have shown that hyperthermia enhances penetration of the cytotoxic agent and induces tumor cell death by multiple mechanisms. These include impairing DNA repair, inhibiting angiogenesis and inducing apoptosis. The treatment rationale is that HIPEC can penetrate and eradicate tumors up to a diameter of $2.5 \mathrm{~cm}$, so 
that any cancer left should be smaller than this for HIPEC to be most effective. Advantages of HIPEC compared with postoperative i.p. chemotherapy are that no adhesion barriers exist at the time of operation and that there is no need of a tenkoff catheter. Furthermore, the effectiveness of intraoperative intraperitoneal chemotherapy is increased by the hyperthermic application (3-8). So far, all these advantages are only theoretical.

While there is data concerning the efficacy of the method, there are hardly any reports as to the side effects of this treatment option. This was enough reason to evaluate the adverse effects of hyperthermic intraperitoneal intraoperative chemotherapy in patients with advanced or recurrent ovarian cancer.

\section{Patients and Methods}

We performed a case series analysis of patients treated with HIPEC for ovarian cancer. An interdisciplinary team of one specialized gynecologic oncologist and abdominal surgeons who performed all surgical procedures according to standard operative treatment guidelines of advanced or recurrent ovarian cancer. Forty three patients were included either with advanced ovarian cancer or with recurrent ovarian cancer between October 2014 and April 2016. The criteria for inclusion were as follows: 1) patients with histopathologically proven primary stage III ovarian, fallopian tube and primary peritoneal carcinoma, 2) patients with intervall debulking surgery after neodadjuvant chenotherapy+, and 3) patients with recurrent ovarian, fallopian tube and primary peritoneal carcinoma.

HIPEC was performed at the end of the operation. All 43 HIPEC procedures were performed using a closed method. Cisplatin was used at a dose of $50 \mathrm{mg} / \mathrm{m}^{2}$ and was diluted in 31 of NaCl solution for peritoneal dialysis. Initially, 31 of a heated perfusion solution was infused into the abdominal cavity at a rate of $1000-3000 \mathrm{ml} / \mathrm{min}$ through the inflow tube using the Bemont Hyperthermic pump. The intraabdominal thermometers (one positioned in the pelvis, and the second in the diaphragma area) were used to monitor the temperature inside the peritoneal cavity during the infusion, which was kept constant at $42^{\circ} \mathrm{C}$. The duration of the HIPEC procedure was $60 \mathrm{~min}$, after which the perfusion solution was completely drained.

In all patients the peritoneal cancer index was routinely determined using the Sugarbaker classification (9). This shows the results of a single institution prospective cohort with 43 patients who after optimal cytoreductive surgery for advanced ovarian cancer with tumor size less than $0.25 \mathrm{~cm}$ were treated with HIPEC (with the exception of one patient). The adverse effects of hyperthermic intraoperative chemotherapy are reported. To analyze the side effects, the Clavido-Dindo classification was used (10).

\section{Results}

Biometric data and the surgical procedures are summarized in Tables I and II. The median age of the patients was 56 years (range $=32-74$ years), the median peritoneal cancer index $(\mathrm{PCI})$ was 13 (range $=4-21)$, the median operation time was $356 \mathrm{minu}$ (range $=192-507 \mathrm{~min})$.
In $40(93.0 \%)$ of the 43 cases a CC- 0 resection was reached. Of these 40 patients, 24 patients were treated by primary debulking surgery, three patients by intervall debulking surgery and 13 patients received surgery for recurrences.

A CC-1 resection was performed in $7.0 \%$ of the cases (primary treatment: $\mathrm{n}=2$, treatment for recurrences: $\mathrm{n}=1$ ).

In these 43 patients, 142 peritonectomy procedures (right and left upper quadrant, paracolic right and left, pelvis, mesenterium, anterior abdominal wall, bursa omentalis) were performed. The median number per patient was 4 procedures (range $=0-8$ procedures). Pelvic peritonectomy was performed in 36 patients $(83.7 \%)$. No peritonectomy was performed in $6(14.0 \%)$ patients, and $25(58.1 \%)$ patients had 4 or more than 4 peritonectomy procedures.

In total, 145 visceral resections were performed in these 43 patients. The median number per patient was 4 resections (range $=0-11$ ). Greater omentectomy was performed in $70.5 \%$ of patients, partial gastrectomy in $2.3 \%$, splenectomy in $18.2 \%$, cholecystectomy in $11.4 \%$ and partial pancreatectomy in $2.3 \%$. Hysterectomy was performed in $63.6 \%$ of patients. In $10(23.3 \%)$ patients, more than 4 visceral resections were performed.

There were three different anastomotic procedures (ileocolic, colocolic, colorectal). The total number of anastomosis in all patients was 56 with a median of 1 per patient (range=0-3). The most common anastomosis was a colorectal anastomosis, which was performed in 36 patients $(83.7 \%)$.

A total of 5 ostomies in $11.6 \%$ of patients were necessary: $4(9.3 \%)$ were diverting ileostomies to protect a colorectal anastomosis and in one case (2.3\%) a permanent colostomy had to be performed.

Thirteen patients $(30.2 \%)$ received 1 to 4 units fresh frozen plasma and $8(18.6 \%)$ patients received more than 4 units. In 9 patients (20.9\%) no fresh frozen plasma (FFP) in the operating room was necessary. Only $6(14.0 \%)$ patients received a transfusion of more than 6 units of whole blood. Nineteen (44.2\%) patients did not need blood transfusions.

All patients were treated with HIPEC with $50 \mathrm{mg} / \mathrm{m}^{2}$ cisplatin in the operating room. There was no early postoperative intraperitoneal chemotherapy added. The median time to postoperative systemic treatment with chemotherapy was 29 days (range $=21-70$ days). There was no postoperative death in this group of 43 patients.

No adverse events were recorded in $16(37.2 \%)$ of the 43 patients, no grade III or IV adverse events were reported for $33(76.7 \%)$ patients, and no grade IV adverse events were reported for $41(95.3 \%)$ patients.

The grade III and IV adverse events are summarized in Table III. Grade III adverse events occured in 19 (44.2\%) of the 43 patients. A total of 29 grade III adverse events were reported in 19 patients. Twelve of these 29 adverse events were pleural effusions after peritonectomy at the diaphragma. Grade IV adverse events occured in 3 (7.0\%) 
Table I. Patient characteristics.

\begin{tabular}{lc}
\hline Patients & $\mathrm{n}=43$ \\
Median age & 56 years (range $=32-74$ years) \\
Median peritoneal cancer index (PCI) & 13 (range $=4-21)$ \\
Median duration of operation & 356 min (range $=192-507$ min) \\
\hline
\end{tabular}

Table II. Surgical procedures.

\begin{tabular}{lc}
\hline Anastomosis & $\mathrm{n}=56$ (from 43 patients) \\
Partial gastric resections & $\mathrm{n}=1$ \\
Splenectomies & $\mathrm{n}=8$ \\
Cholecystectomies & $\mathrm{n}=5$ \\
Protective ileostomies & $\mathrm{n}=5$ \\
Insufficiencies of anastomoses & $\mathrm{n}=0$ \\
Leakages induced by drainages & $\mathrm{n}=1$ \\
\hline
\end{tabular}

of the 43 patients. A total of 3 grade IV adverse events were reported.

Two grade IV adverse events resulted in return to the operating room. This was a fistula of the distal small bowel caused by drainage and a revision of wound infection. The remaining grade IV adverse events did not require surgical intervention.

\section{Discussion}

Ovarian cancer is a leading cause of cancer related death in women and is often only diagnosed at an advanced stage, then with diffuse peritoneal carcinomatosis. Since ovarian cancer is mainly confined to the peritoneal cavity, even after recurrence, it is an ideal target for locoregional therapy. Up until recently, most of the evidence for HIPEC in the treatment of advanced ovarian cancer was based on large retrospective series (11-13), a few small non-randomized prospective studies $(14,15)$ and a small randomized trial of low quality in terms to study design (16). These available studies are difficult to interpret and compare due to the heterogeneiety of the study groups. A clear distinction between primary and recurrent disease, extensiveness of peritonectomy surgery, various FIGO stages and types of histology, although these aspects significantly influence the outcome. A systemic review of published trials (17) identified 9 comparative studies reporting an improvement in survival following cytoreductive surgery (CRS ) and HIPEC [+/- chemotherapy (CHT)] compared with CRS alone (+/- CHT). Morbidity following CRS and HIPEC has been reported to be between $12 \%$ and $33 \%(17,18)$. The
Table III. Adverse events grade III and IV.

\begin{tabular}{lcc}
\hline Adverse events & Grade III & Grade IV \\
& $\mathrm{n}$ & $\mathrm{n}$ \\
\hline Total adverse events & 29 at 19 pat. & 3 at 3 pat. \\
& $(44.2 \%)$ & $(7.0 \%)$ \\
Haematology & 10 & 0 \\
Leucocytopenia/thrombocytopenia & 3 & 0 \\
Transfusion $>4$ units & 7 & 0 \\
Renal failure & 2 & 0 \\
Electrolyte abnormalities & 1 & 0 \\
Pleural effusions & 12 & 0 \\
Gastrointestinal & 1 & 0 \\
Insufficiencies of anastomoses & 0 & 0 \\
Fistula & 0 & 1 \\
Infections & 2 & 0 \\
Thromboembolism & 1 & 0 \\
Cardiac events (reanimation) & 0 & 1 \\
Wound infection with operative revision & 0 & 1 \\
\hline
\end{tabular}

majority of complications are more likely due to the aggressive CRS rather than HIPEC, particularly in respect to bowel complications (anastomotic insufficiences, bowel fistula sepsis). However, the addition of HIPEC is associated with renal impairment and haematological toxicity due to transient bone marrow suppression.

The results of the first RCT for HIPEC for primary ovarian cancer were published in 2018 (19). In this study, hyperthermic intraperitoneal chemotherapy with $100 \mathrm{mg} / \mathrm{m}^{2}$ cisplatin was administered at $40^{\circ} \mathrm{C}$ over $90 \mathrm{~min}$ in an open technique. Sodium thiosulfate was administered by a six-hour intravenous infusion to prevent nephrotoxicity. The hazard ratio (HR) for disease recurrence or death was 0.66 (95\% CI=0.50-0.87, $p=0.003$ ), favouring the HIPEC group. The median PFS was 14.2 months in the CRS plus HIPEC group versus 10.7 months in the CRS group. At 5 years, $50 \%$ of the patients in the CRS plus HIPEC group had died versus $62 \%$ in the CRS group $(\mathrm{HR}=0.67,95 \% \mathrm{CI}=0.48-0.94, p=0.02)$. The median OS was 45.7 months versus 33.9 months, showing a 11.8-month survival advantage in the CRS plus HIPEC group. There was no significant difference in grade III or IV adverse events between the two groups (27\% vs. $25 \%$, $p=0.76$, respectively). There was a higher rate of stoma formation in the CRS plus HIPEC group ( $72 \%$ vs. $43 \%$, $p=0.04)$. Despite this, the overall health-related quality of life outcomes did not differ between the two groups. To date this is the best evidence that a single administration of HIPEC given at the time of cytoreductive surgery for ovarian cancer may achieve significant benefits in terms of survival without excess morbidity or loss of quality of life. However, there has been a critique concerning this study, in the direction of a 
possible premature analysis of overall survival, the heterogeneity of results between study centres, and the results being applicable to only a small subset of patients with ovarian cancer (20). The HIPEC arm also received an additional, high dose of cisplatin compared to the non-HIPEC arm, which in itself might explain the improved survival.

In contrast to the results of this aforementioned study, preliminary results from a smaller Korean RCT of HIPEC in 184 women with stage III and IV ovarian cancer failed to show a significant difference in five-year survival in the HIPEC arm (21). Yet it remains unclear how many women in this study had residual disease less than $2.5 \mathrm{~mm}$. Also, cases of stage IV disease were included. Given the importance of achieving minimal residual disease confined to the peritoneal cavity for HIPEC to be most effective, the results of the Korean trial must be analysed more thoroughly before conclusions can be drawn about the validity of these findings. More recently, a phase III RCT of HIPEC for stage IV colorectal cancer did not show a survival benefit over systemic chemotherapy following cytoreductive surgery (22).

As yet, the type of medication used and dose of intraperitoneal chemotherapy remains unclear. In the first German prospective HIPEC ROC I trial with 12 patients suffering from recurrent ovarian cancer, Zivanovic et al. (23) demonstrated that increasing dosages from $50 \mathrm{mg} / \mathrm{m}^{2}$ cisplatin to $100 \mathrm{mg} / \mathrm{m}^{2}$ are safe. Thus, the conclusion was that $100 \mathrm{mg} / \mathrm{m}^{2}$ cisplatin should be used in future studies. They observed one case of renal failure without the need for dialysis. The mean operation time was $463 \mathrm{~min}$ and the time to systemic chemotherapy was no longer than 6 weeks. In this case series the dosage of $50 \mathrm{mg} / \mathrm{m}^{2}$ cisplatin was used, because the results of Zivanovic et al. (23) were not available when our case series started. Furthermore, we did not want to influence the incidence of adverse events negatively with the risk of prolonging the time to systemic chemotherapy (TTC).

When exactly postoperative systemic chemotherapy (TTC) should begin remains controversial. The main prognostic factor for survival is the radicality of debulking surgery with the aim of achieving CC-0 resection. Nevertheless, in a systemic review of 3.326 patients of the AGO-OVAR trials 3, 5, and 7 Mahner et al. (24) showed that a time interval to chemotherapy of more than 19 days is combined with a significant decline in prognosis, especially for those patients without macroscopic residual tumor after debulking surgery. These results stand in concordance to the results of Hofstetter et al. (25). They evaluated the data of 191 patients of the European multicenter OVCAD trial in which patients had a median time to chemotherapy of 28 days (range $=4-158$ days). They could show that patients with remaining tumor after debulking surgery had a significantly worse overall survival when starting chemotherapy later than 28 days after CRS. Feng et al. (26) have reported on 625 patients with advanced ovarian cancer and a median time to chemotherapy of 15 days (range=4-62 days). They could demonstrate that a time to chemotherapy of up to 6 weeks does not negatively effect the prognosis. In our trial the median time to chemotherapy was 29 days with a range of 21 to 70 days. The patient with a TTC of 70 days that negatively influenced the total result of TTC was the patient with a fistula of the ileum caused by a drainage resulting in several operations.

As already pointed out above, the most important prognostic factor is the radicality of cytoreductive surgery (CRS) with a significantly better prognosis for patients with total tumor resection after CRS. (27-30). Hofstetter et al. (25) have described a $\mathrm{R} 0$ resection in $63.4 \%$ of the patients in their trial and Feng et al. of $33.4 \%$. In $93.0 \%$ of the patients of our case series a CC- 0 resection and in $7.0 \%$ a CC- 1 resection was achieved. Thus, the number of patients with $\mathrm{CC}-0$ resection in our case series is significantly higher than in the comparable studies of Hofstetter et al. (25) and Feng et al. (26).

In our case series adverse events of grade III following the Clavien Dindo classification (10) were observed in 19 patients (44.2\%) with 29 grade III adverse events. Twelve of these 29 adverse events were pleural effusions after peritonectomy at the diaphragma. There were 3 adverse events of grade IV in our case series: one small bowel fistula caused by the drainage had to be reoperated, one succesful cardiopulmonary reanimation and one wound infection with secondary operative revision. All these adverse events occured in three patients $(7.0 \%)$. There was no postoperative death.

In their trail with 142 patients with colorectal carcinomas and CRS with HIPEC Yonemura et al. (31) have reported one postoperative death due to pulmonary thromboembolism. Grade III adverse events were described in $7.7 \%$ and grade IV adverse events in $9.9 \%$ of cases, mainly concerning anastomotic insufficiencies and fistulas of the bowel. Pleural effusions were not reported. Kuijpers et al. (32) have reported grade III adverse events in 34\% of the 960 patients with colorectal tumors treated by CRS and HIPEC. Three \% of the patients died after surgery. Passot et al. (33), with 216 patients with peritoneal carcinomatosis of different origin (35\% ovarian cancer) treated with CRS and HIPEC have reporteda $42 \%$ incidence of grade III and IV adverse events.

The fact that we had a high rate of $\mathrm{CC}-0$ resection and different peritoneal and anastomotic procedures in our case series, makes it difficult to compare our data to the above mentioned literature concerning morbidity and mortality.

Because of our heterogenous cohort no survival data can be presented. The main aim was to evaluate the feasibility and morbidity of HIPEC combined with cytoreductive surgery followed by standard platin and taxan based chemotherapy. CRS and HIPEC with $50 \mathrm{mg} / \mathrm{m}^{2}$ cisplatin in ovarian cancer is a feasable treatment option. The time to chemotherapy (TTC) in our setting was not markedly prolonged. The main complications are surgically caused and not the result of the 
HIPEC procedure. The low incidence of grade III and IV adverse events without any perioperative mortality in our case series suggests that HIPEC with $50 \mathrm{mg} / \mathrm{m}^{2}$ cisplatin after CRS in ovarian cancer does not cause intolerable adverse events or is of disadvantage for patients with ovarian cancer. The very low leakage rate with only one case of a fistula of the small bowel shows the immense importance of the experience of the surgical team and the complication rate with respect to insufficiences of anastomoses.

In summary, the data presented is not a proof of the efficacy for the approach with HIPEC in the treatment of ovarian cancer which is an experimental one at the moment. It has to be emphasized that HIPEC is currently only indicated by National Comprehensive Cancer Network ${ }^{\circledR}$ (NCCN) guidelines for administration in the interval debulking setting, in patients with stage III disease. There is currently no indication in the recurrent setting or after primary debulking surgery.

Conclusively, cytoreductive surgery with the use of HIPEC should not be performed outside these guidelines unless there are study conditions in experienced centers. Prospective trials are needed.

\section{Conflicts of Interest}

The Authors declare no conflicts of interest related to this study.

\section{Authors' Contributions}

Prof. Dr. Clayton Kraft: Translation; Prof. Dr. Walther Kuhn: Corrections in form and content; Wolfgang Zinn: Analysis and interpretation of data; Prof. Dr. Michael Friedrich: Surgeon; Laura Kolnsberg: Medical care during hospital stay.

\section{References}

1 RKI. Available at: https://www.krebsdaten.de/Krebs/DE/ Content/Krebsarten/Ovarialkrebs/ovarialkrebs_node.html [Last accessed on 16/01/20]

2 Jaaback K, Johnson $\mathrm{N}$ and Lawrie TA: Intraperitoneal chemotherapy for the initial management of primary epithelial ovarian cancer. The Cochrane database of systematic reviews 1: CD005340, 2016. DOI: 10.1002/14651858.CD005340.pub4

3 Farrell R: Is peritonectomy and hyperthermic intraperitoneal chemotherapy a new standard of treatment for advanced epithelial ovarian cancer? Aust N Z J Obstet Gynaecol 59: 335340, 2019. PMID: 30706448. DOI: 10.1111/ajo.12953

4 Ohno S, Siddik ZH, Kido Y, Zwelling LA and Bull JM: Thermal enhancement of drug uptake and DNA adducts as a possible mechanism for the effect of sequencing hyperthermia on cisplatin-induced toxicity in L1210 cells. Cancer Chemother Pharmacol 34: 302-306, 1994. PMID: 8033297. DOI: 10.1007/ bf00686037

5 Van de Vaart PJ, van der Vange N Zoetmulder FA, van Goethem AR, van Tellingen $\mathrm{O}$, ten Bokkel Huinink WW, Beijnen JH, Bartelink $\mathrm{H}$ and Begg AC: Intraperitoneal cisplatin with regional hyperthermia in advanced ovarian cancer: pharmacokinetics and
cisplatin-DANN adduct formation in patients and ovarian cancer cell lines. Eur J Cancer 34: 148-154, 1998. PMID: 9624250. DOI: $10.1016 / \mathrm{s} 0959-8049(97) 00370-5$

6 Los G, Mutsaers PHA, van der Vijgh WJF and Mc Vie JG: Direct diffusion of cis-diamminedichloroplatinum (II) in intraperitoneal rat tumours after intraperitoneal chemotherapy: a comparison with systemic chemotherapy. Cancer Res 49: 33803384, 1989. PMID: 2720692.

7 Spratt JS, Adcock RA, Muskovin M, Sherrill W and McKeown $\mathrm{J}$ : Clinical delivery system for intraperitoneal hyperthermic chemotherapy. Cancer Res 40: 256-260, 1980. PMID: 6766084.

8 Blinman P, Gainford C, Donoghoe M, Martyn J, Blomfield P, Grant P, Kichenadasse G, Vaughan M, Brand A, Shannon C, Gebski V, Stockler $M$ and Friedlander M: Feasibility, acceptability, and preferences for intraperitoneal chemotherapy with paclitaxel and cisplatin after optimal debulking surgery for ovarian and related cancers: an ANZGOG study. J Gynecol Oncol 24: 359-366, 2013. PMID: 24167672. DOI: 10.3802/ jgo.2013.24.4.359

9 Sugarbaker PH: Peritonectomy procedures. Ann Surg 221(1): 2942, 1995. PMID: 7826158. DOI: 10.1097/00000658-19950100000004

10 Dindo D, Demartines $\mathrm{N}$ and Clavien PA: Classification of surgical complications. Ann Surg 240(2): 205-213, 2004. DOI: 10.1097/01.sla.0000133083.54934.ae

11 Bakrin N, Bereder JM, Decullier E, Classe JM, Msika S, Lorimier G, Abboud K, Meeus P, Ferron G, Quenet F, Marchal F, Gouy S, Morice P, Pomel C, Pocard M, Guyon F, Porcheron J and Glehen O; FROGHI (FRench Oncologic and Gynecologic HIPEC) Group: Peritoneal carcinomatosis treated with cytoreductive surgery and hyperthermic intraperitoneal chemotherapy (HIPEC) for advanced ovarian carcinoma: a French multicentre retrospective cohort study of 566 patients. Eur J Surg Oncol 39: 1435-1443, 2013. PMID: 24209430. DOI: 10.1016/j.ejso.2013.09.030

12 Di Gorgio A, De Iaco P, De Simone M, Garofalo A, Scambia G, Pinna $\mathrm{AD}$, Verdecchia GM, Ansaloni L, Macrì $\mathrm{A}$, Cappellini $\mathrm{P}$, Ceriani V, Giorda $G$, Biacchi D, Vaira $M$, Valle $M$ and Sammartino P: Cytoreduction (peritonectomy procedures) combined with hyperthermic intraperitoneal chemotherapy (HIPEC) in advanced ovarian cancer: retrospective Italian multicentre observational study of 511 cases. Ann Surg Oncol 24: 914-922, 2016. PMID: 27896512. DOI:10.1245/s10434-016$5686-1$

13 Munoz-Casares FC, Medina-Fernandez FJ, Arjona-Sanchez A, Casado-Adam Á, Sánchez-Hidalgo JM, Rubio MJ, Ortega-Salas $\mathrm{R}$, Muñoz-Villanueva MC, Rufián-Peña $\mathrm{S}$ and Briceño FJ: Peritonectomy procedures and HIPEC in the treatment of peritoneal carcinomatosis from ovarian cancer: long term outcomes and perspectives from a high-volume center. Eur J Surg Oncol: 42: 224-233, 2016. PMID: 26673283. DOI: 10.1016/j.ejso.2015.11.006

14 Coccolini F, Campanati L, Catena F, Ceni V, Ceresoli M, Jimenez Cruz J, Lotti M, Magnone S, Napoli J, Rossetti D, De Iaco P, Frigerio L, Pinna A, Runnebaum I and Ansaloni L: Hyperthermic intraperitoneal chemotherapy with cisplatin and paclitaxel in advanced ovarian cancer: a multicentre prospective observational study. J Gynecol Oncol 26: 54-61, 2015. PMID: 25376916. DOI: 10.3802 jgo.2015.26.1.54

15 Deraco M, Kusamura S, Virzi S, Puccio F, Macrì A, Famulari C, Solazzo M, Bonomi S, Iusco DR and Baratti D: Cytoreductive 
surgery and hyperthermic intraperitoneal chempotherapy as upfront therapy for advanced epithelial ovarian cancer: multiinstitutional phase-II trial. Gynecol Oncol 122: 215-220, 2011. PMID: 21665254. DOI: 10.1016/j.ygyno.2011.05.004

16 Spiliotis J, Halkia E, Lianos E, Kalantzi N, Grivas A, Efstathiou $\mathrm{E}$ and Giassas S: Cytoreductive surgery and HIPEC in recurrent epithelial ovarian cancer: a prospective randomised phase III study. Ann Surg Oncol 22: 1570-1575, 2015. PMID: 25391263. DOI: $10.1245 / \mathrm{s} 10434-014-4157-9$

17 Huo YR, Richards A, Liauw W and Morris DL: Hyperthermic intraperitoneal chemotherapy (HIPEC) and cytoreductive surgery (CRS) in ovarian cancer: a systematic review and meta-analysis. Eur J Surg Oncol 41: 1578-1589, 2015. PMID: 26453145. DOI: 10.1016/j.ejso.2015.08.172

18 Hotouras A, Desai D, Bhan C Murphy J, Lampe B and Sugarbaker PH: Heated intraperitoneal chemotherapy (HIPEC) for patients with recurrent ovarian cancer: a systematic literature review. Int J Gynecol Cancer 26: 661-670, 2016. PMID: 26844612. DOI: $10.1097 /$ IGC.0000000000000664

19 Van Driehl WJ; Koole SN; Sikorska K, Schagen van Leeuwen JH, Schreuder HWR, Hermans RHM, de Hingh IHJT, van der Velden J, Arts HJ, Massuger LFAG, Aalbers AGJ, Verwaal VJ, Kieffer JM, Van de Vijver KK, van Tinteren H, Aaronson NK and Sonke GS: Hyperthermic intraperitoneal chemitherapy in ovarian cancer. N Engl J Med 378: 230-240, 2018. PMID: 29342393. DOI: $10.1056 /$ NEJMoa1708618

20 Fotopoulou C, Sehouli J, Mahner S, Harter P, Van Nieuwenhuysen E, Gonzalez-Martin A, Vergote I, Chiva L and Du Bois A: HIPEC: Hope or hype in the fight against advanced ovarian cancer? Ann Oncol 29: 1610-1613, 2018. PMID: 29873689. DOI: $10.1093 /$ annonc/mdy 198

21 Lim MC, Chang SJ, Yoo HJ, Nam BH, Bristow R and Park SY: Randomised trial of hyperthermic intraperitoneal chemotherapy (HIPEC) in women with advanced peritoneal, ovarian and tubal cancer. J Clin Oncol 35: 5520, 2017. DOI: 10.1200/JCO.2017. 35.15_suppl.5520

22 Quenet F, Elias D, Roca, Goere D, Ghouti L, Pocard M, Facy O, Arvieux C, Lorimier G, Pezet D, Marchal F, Loi V, Meeus P, De Forges H, Stanbury T, Paineau $J$ and Glehen O: A UNICANCER phase III trial of hyperthermic intraperitoneal chemotherapy (HIPEC) for colorectal carcinomatosis (PC): PRODIGE 7. J Clin Oncol 36(18_suppl): LBA3503-LBA3503, 2018. DOI: $10.1016 /$ j.ejso.2018.10.086

23 Zivanovic O, Abramian A, Kullmann M, Fuhrmann C, Coch C, Hoeller T, Ruehs H, Keyver-Paik MD, Rudlowski C, Weber S, Kiefer N, Poelcher ML, Thiesler T, Rostamzadeh B, Mallmann M, Schaefer N, Permantier M, Latten S, Kalff J, Thomale J, Jaehde U and Kuhn WC: HIPEC ROC I: A phase I study of cisplatin administered as hyperthermic intraoperative intraperitoneal chemoperfusion followed by postoperative intravenous platinum-based chemotherapy in patients with platinum-sensitive recurrent epithelial ovarian cancer. Int J Cancer 136(3): 699-708, 2015. PMID: 24895230. DOI: 10.1002/ijc.29011

24 Mahner S, Eulenburg C, Staehle A, Wegscheider K, Reuss A, Pujade-Lauraine E, Harter P, Ray-Coquard I, Pfisterer J and du Bois A: Prognostic impact of the time interval between surgery and chemotherapy in advanced ovarian cancer: analysis of prospective randomised phase III trials. Eur J Cancer 49(1): 142149, 2013. PMID: 22921185. DOI: 10.1016/j.ejca.2012.07.023
25 Hofstetter G, Concin N, Braicu I, Chekerov R, Sehouli J, Cadron I, Van Gorp T, Trillsch F, Mahner S, Ulmer H, Grimm C, Castillo-Tong DC, Zeillinger R, Zeimet AG and Vergote I: The time interval from surgery to start of chemotherapy significantly impacts prognosis in patients with advanced serous ovarian carcinoma - analysis of patient data in the prospective OVCAD study. Gynecol Oncol 131(1): 15-20, 2013. PMID: 23877013. DOI: $10.1016 /$ j.ygyno.2013.07.086

26 Feng Z, Wen H, Bi R, Yang W and Wu X: Prognostic impact of the time interval from primary surgery to intravenous chemotherapy in high grade serous ovarian cancer. Gynecol Oncol 141(3): 466-470, 2016. PMID: 27098361. DOI: 10.1016/j.ygyno.2016.04.016

27 Cliby WA, Powell MA, Al-Hammadi N, Chen L, Philip Miller J, Mutch DG and Bristow RE: Ovarian cancer in the United States: contemporary patterns of care associated with improved survival. Gynecol Oncol 136(1): 11-17, 2015. PMID: 25449311. DOI: $10.1016 /$ j.ygyno.2014.10.023

28 Bristow RE, Tomacruz RS, Armstrong DK, Trimble EL and Montz FJ: Survival effect of maximal cytoreductive surgery for advanced ovarian carcinoma during the platinum era: a metaanalysis. J Clin Oncol 20(5): 1248-1259, 2002. PMID: 11870167. DOI: $10.1200 / J C O .2002 .20 .5 .1248$

29 Harter P, Beutel B, Alesina PF, Lorenz D, Boergers A, Heitz F, Hils R, Kurzeder C, Traut A and du Bois A: Prognostic and predictive value of the Arbeitsgemeinschaft Gynaekologische Onkologie (AGO) score in surgery for recurrent ovarian cancer. Gynecol Oncol 132(3): 537-541, 2014. PMID: 24462732. DOI: 10.1016/j.ygyno.2014.01.027

30 Wimberger P, Lehmann N, Kimmig R, Burges A, Meier W, Du Bois A and Arbeitsgemeinschaft Gynaekologische Onkologie Ovarian Cancer Study Group: Prognostic factors for complete debulking in advanced ovarian cancer and its impact on survival. An exploratory analysis of a prospectively randomized phase III study of the Arbeitsgemeinschaft Gynaekologische Onkologie Ovarian Cancer Study Group (AGO-OVAR). Gynecol Oncol 106(1): 69-74, 2007. PMID: 17397910. DOI: 10.1016/j.ygyno.2007.02.026

31 Yonemura Y, Canbay E and Ishibashi H: Prognostic factors of peritoneal metastases from colorectal cancer following cytoreductive surgery and perioperative chemotherapy. ScientificWorldJournal 2013: 978394, 2013. PMID: 23710154. DOI: $10.1155 / 2013 / 978394$

32 Kuijpers AMJ, Mirck B, Aalbers AGJ, NienhuijsSW, de Hingh IJHT, Wiezer MJ, van Ramshorst B, van Ginkel RJ and Havenga $\mathrm{K}$ : Cytoreduction and HIPEC in the Netherlands: nationwide long-term outcome following the Dutch protocol. Ann Surg Oncol 20(13): 4224-4230, 2013. PMID: 23897008. DOI: 10.1245/s10434-013-3145-9

33 Passot G, Bakrin N, Roux AS, Vaudoyer D, Gilly FN, Glehen O and Cotte E: Quality of life after cytoreductive surgery plus hyperthermic intraperitoneal chemotherapy: a prospective study of 216 patients. Eur J Surg Oncol 40(5): 529-535, 2014. PMID: 24370285. DOI: $10.1016 /$ j.ejso.2013.11.019

Received January 8, 2020

Revised January 23, 2020 Accepted January 27, 2020 